\title{
Intelligent System for Fault Detection in Wind Turbines Gearbox
}

\author{
R. F. Mesquita Brandão \\ J. A. Beleza Carvalho \\ ISEP/IPP \\ Porto, Portugal \\ rfb@isep.ipp.pt
}

\author{
F.P.Maciel Barbosa \\ FEUP \& INESC TEC \\ Porto,Portugal \\ fmb@fe.up.pt
}

\begin{abstract}
New generations of turbines have lower repair and maintenance costs than the previous generation. This is justified by the development of new components and materials. As the power of newer turbines is usually substantially larger, it is possible to get an economy of scale and lower maintenance costs per $\mathrm{kW}$ of rated power. This is simply because it is not needed to service a large turbine more often than a small one.
\end{abstract}

New methods of earlier detection of faults are needed. The use of all information from SCADA (Supervisory Control and Data Acquisition) system can be useful, but it is necessary to develop tools to deal with bigger amount of information. Neural networks can help and turn possible new maintenance and operation schemes.

Index Terms - Fault detection, Neural networks, SCADA systems, Wind energy.

\section{INTRODUCTION}

In the past the wind industry used maintenance based in the running time of the generator. However, as wind turbines have increased in capacity, preventive maintenance is becoming increasingly adopted (following the wind turbine manufacturer's service manual) with many operators now employing periodic inspections to evaluate the wind turbine conditions based on empirical and subjective measures [1]. Such inspections are generally costly, intrusive and often require undesirable interruptions for its realization.

Although turbines maintenance is done periodically, usually twice a year for almost wind turbines equipment's, this strategy has as result the fact that the equipment is not monitored between maintenances.

Wind turbines availability is increased by maximizing the time between repairs and revisions, planning in advance the most appropriate maintenance intervals, the logistics needed, the spare parts and the work hours required. One important factor that influences the planning of maintenance actions is the weather. If weather conditions do not allow access to the turbines, the maintenance is not done. On the other hand, if there are ideal conditions for the production of energy, hardly the owner of the park authorize the shutdown of the machines, with the consequent loss of production, to do the maintenance operations.

Modern wind turbines are acquired with a full service contract with a term which usually is around 2-5 years warranty and that includes strategies for corrective and preventive maintenance. Usually these maintenance strategies are continued by wind farms operators at the end of the contract period [2].

Normally maintenance is based in the wind turbine manufacturer's service manual and on periodic inspections made by maintenance teams and can be considered as a fixed amount of money paid for a regular service. In spite of this, maintenance costs can be considerable reduced with the increase of power of modern turbines, as the costs of these actions are similar for large and small turbines. The development of new techniques to detect in advance faults is very useful to optimize the maintenance costs and increase the reliability of the turbines.

\section{IMPORTANCE OF MAINTENANCE}

The maintenance of wind systems, as any industrial system is classified into two types, corrective and preventive maintenance. The unplanned or emergency maintenance is associated with the rupture of a material or equipment and the need for placing the material in immediate operation.

Corrective maintenance is performed after the occurrence of the anomaly and its objective is to repair the system. Interventions for overall improvement of the equipment may also be made even without malfunction occurrence.

Preventive maintenance is performed on predetermined periods of time or according to a given criterion, with the objective of reducing the probability of occurrence of a malfunction. There are two types of preventive maintenance: the systematic or planned maintenance and the conditioned- 
based maintenance, differing only by the method of decision for maintenance performing.

The planned maintenance, when associated to wind turbines, typically includes lubrication actions, screws tightening, changing filters and checking safety equipment.

Condition based maintenance is a preventive maintenance that is based on the performance and equipment monitoring, through monitoring systems [3].

Any maintenance strategy, if exists, can combine all three methods, since it will be a combination of corrective and preventive maintenance.

In order to have a good understanding of the problems of maintenance management is necessary to understand the time periods associated with the functioning and stopping of equipment. It is also necessary to understand the concept of reliability and maintainability of a system.

These concepts, although very similar, does not mean the same thing. According to [4], reliability is the ability of a system or component to perform its functions under certain conditions and for a certain period of time. Maintainability is the ability from one installation to be maintained or restored in availability status, being the maintenance carried out under appropriate conditions, with the procedures and means foreseen [5].

There are some indicators that can be used to evaluate the performance of the systems, taking into account the number and duration of interruptions. The mean time to failure (MTBF) and mean time to repair (MTTR) are two of them.

Nowadays, most of wind turbine producers impose a maintenance strategy based on time in which maintenance teams go regularly to the turbine to make inspections, repairs and substitution of equipment's. Normally two maintenances are made per year. This systematic maintenance is based in pre-defined tasks in were maintenance teams know exactly what to do. Due to safety restrictions the maintenance can only be performed under specific weather conditions.

Maintenance strategy based on time, has some handicaps. If time interval between maintenances is to short, operational costs increases and wind turbine outage time increases too, due to the necessity of stop the machine to do the work. On the other hand, more unexpected faults occur when time interval between inspections is long.

To solve this paradigm some producers and wind park owners started to develop maintenance strategies based on equipment condition monitoring. Using these techniques is possible to optimize the maintenance as a way to increase the availability and reduce operational costs.

One of the major problems is the inherent cost when is necessary to implement new methods to detect early faults in some wind turbine components. Installation of new sensors, or new communication systems or even new software for data analysis can be necessary. For this reason new methods developed must have this into attention and try to give good results without being expensive. New method presented here only use the SCADA information and don't need to install new components. This can be an important issue to have in attention by wind farm operators.

\section{NEW METHOD TO FAULT DETECTION}

Although the typical price of replacement components (set of rotor blades, a gearbox and generator) is $15 \%-20 \%$ of the price of a new turbine, a thorough check has to be made to the existing components to be sure that they are safe and suitable [6].

With forecast of certain faults it is possible to optimize the maintenance and define a proper programming of maintenance actions to be performed and materials to be used.

Faults are problems that should be avoided at all costs in any equipment and especially in a wind turbine. The resolution of a fault, usually involves the movement of skilled personnel to the wind park location. If the fault leads to the halt of the equipment, losses will accumulate, associated to the cost of solving the problem that have to be add up to the costs associated with the downtime of the wind turbine.

In the failure analysis of wind turbines, there are three devices that due to their size, costs associated with replacement and downtime associated with a repair or replacement, deserve a special attention by the monitoring systems. They are the blades, the gearbox and the electric generator.

Many wind turbine manufacturers have software tools that, based on SCADA systems, make possible to understand the operating status of the equipment and with that, schedule the equipment maintenance. However, many of these tools are based on the comparison of the real state of the equipment with average values and cannot be considered a true fault prediction tool.

The use of a large number of data recorded by the SCADA system of a wind park can be helpful in predicting faults.

This technology was tested [7] for the prediction of faults in gearboxes and electric generator of a wind farm located in Portugal. The results obtained showed that it is possible to detect, in advance, some faults.

The developed technology is based on the use of neural networks and SCADA measurements acquired in the park and have the great advantage of not requiring installation of new components. This new tool can be considered a very desirable tool from economical point of view because it is not intrusive and does not require the need for new measurement equipment.

This tool makes use of feedforward neural networks trained with the backpropagation algorithm. The difficulty arises in the choice of the data set used for training the network, which should be representative of the proper functioning of the equipment under monitoring. The training set must contain at least six months of turbine measures and has to be able to predict the variable that is representative of the equipment under monitoring.

In this type of neural networks neurons are organized in form of layers and each neuron of a layer is connected with 
all other neurons of next layer. The information is projected strictly from the input layer towards the output layer. Each connection has a specific weight, which represents the connection strength. It is the adjustment of these weights which is undertaken during network training. The training begins with random weights, and the goal is to adjust them so that the error will be minimal. During this process information can flow both sides. Fig. 1 presents the network architecture used in the monitoring process.

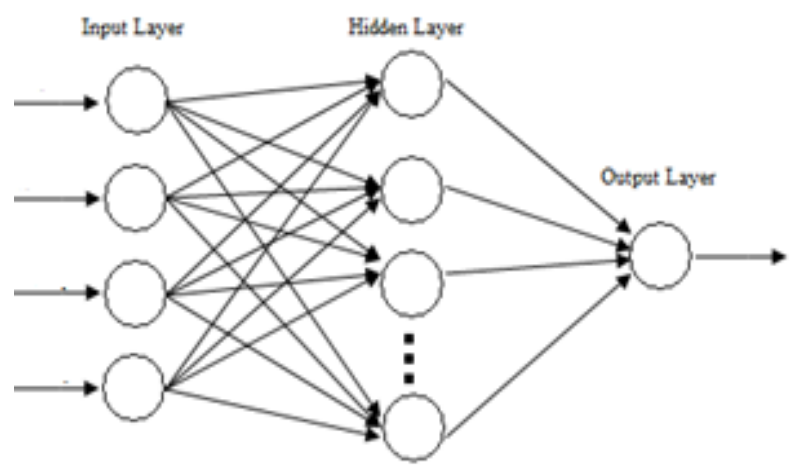

Figure 1. Neural networks architecture

The main goal is to understand which measurements are important to use as input of the neural network, because some measurements can have a weak influence on the process and it only contributes to wasting computational time. To solve this issue is necessary to make an extensive analysis to the data set.

This tool was tested in a wind farm in Portugal composed by 13 wind turbines of $2 \mathrm{MW}$ each, and allowed detection of cracks in the gearbox body and the consequently oil leaks in gearboxes with 4 months in advance [7].

This new intelligent tool is also being used into a US wind farm, composed by 69 wind turbines of $1.5 \mathrm{MW}$ each, testing if it is possible to make the early detection of some gearbox faults. Results obtained until now show that this new detection tool can detect some faults in advance.

Results of the test in the two wind farms will be presented and discussed in this paper.

This new software tool can also be used to verify if maintenance actions performed by the maintenance teams were well executed, because after maintenance actions performed, the indicator used to control the performance of the neural network allows to draw conclusions on this subject.

\section{RESULTS AND DISCUSSION}

Tables I, II and III show the results of simulations made by the application of the neural network model developed to detect faults in the gearbox of the wind turbines.

The criterion used to evaluate the presence of faults in the gearbox is the mean absolute error (MAE), which is given by the following equation:

$$
M A E=\frac{1}{n} \sum_{i=1}^{n} \sqrt{e_{i}^{2}}
$$

where $e_{i}$ represents the difference between the real gearbox oil temperature and the estimated one [8].

A MAE greater than a determined value indicates that something wrong has occurred in the electrical generator.

Table I presents, the results of the MAE obtained for a wind turbine with no problems in the gearbox. Table III shows the results for a wind turbine with a fault in the gearbox [7].

TABLE I.

SIMULATION FOR A WIND TURBINE WITH NO PROBLEMS IN GEARBOX

\begin{tabular}{|c|c|c|c|}
\hline & $\mathbf{2 0 0 6}$ & $\mathbf{2 0 0 7}$ & $\mathbf{2 0 0 8}$ \\
\hline Jan & 1.163 & 1.107 & 1.193 \\
\hline Feb & 2.315 & 1.630 & 1.458 \\
\hline Mar & 5.276 & 1.279 & 1.240 \\
\hline Apr & 0.958 & No data & 1.353 \\
\hline May & 1.171 & 1.288 & 1.393 \\
\hline Jun & 1.134 & 1.377 & 1.412 \\
\hline Jul & 1.199 & 1.346 & 1.509 \\
\hline Aug & 1.441 & 1.411 & 1.383 \\
\hline Sep & 1.142 & 1.403 & 1.355 \\
\hline Oct & 1.320 & 1.621 & 2.066 \\
\hline Nov & 1.090 & 1.363 & 2.353 \\
\hline Dec & 1.020 & 1.459 & 2.169 \\
\hline
\end{tabular}

Simulations were made for 3 years of operation of the wind park in the North of Portugal. As it is possible to see from Table I, MAE is generally always lower than $2^{\circ} \mathrm{C}$. In March of 2006 there is a high value, which can indicate that something is wrong with the gearbox.

The maintenance team was called to check out a high alarm temperature reached by the gearbox oil. The service report drafted by the maintenance team indicates that the oil pump gear box was defective.

Analyzing the values in the table is possible to see that the problem occurred with the oil pump was detected in February, i. e., one month in advance.

From October of 2008 the MAE is higher than $2^{\circ} \mathrm{C}$, value used as trigger alarm. Service reports made by the maintenance teams in the end of 2008 reports some leaks in the gearbox. Those leaks were considered normal for that kind of equipment and are not due to cracks in the body.

Table II shows the MAE simulation results obtained with the application of the developed neural network model to a gearbox from the Park with problems.

Analyzing the results presented in Table II it is possible to verify that during the years of 2006 and 2007, the MAE indicator show normal values, concluding that the gear box is 
working correctly. Also the service reports drawn up during that period do not indicate any serious failure in equipment [7].

TABLE II.

SIMULATION FOR A WIND TURBINE WITH PROBLEMS IN GEARBOX - A

\begin{tabular}{|c|c|c|c|}
\hline & $\mathbf{2 0 0 6}$ & $\mathbf{2 0 0 7}$ & $\mathbf{2 0 0 8}$ \\
\hline Jan & 1.056 & 1.156 & 1.194 \\
\hline Feb & 1.006 & 1.597 & 1.264 \\
\hline Mar & 1.065 & 1.272 & 1.412 \\
\hline Apr & 1.046 & No data & 2.157 \\
\hline May & 1.025 & 1.244 & 1.742 \\
\hline Jun & 1.080 & 1.207 & 2.282 \\
\hline Jul & 1.113 & 1.640 & 2.574 \\
\hline Aug & 1.051 & 1.639 & 3.374 \\
\hline Sep & 1.190 & 1.851 & 2.137 \\
\hline Oct & 1.176 & 1.850 & 2.664 \\
\hline Nov & 1.143 & 1.584 & 2.447 \\
\hline Dec & 1.015 & 1.391 & 2.437 \\
\hline
\end{tabular}

In June 2008, the MAE reached high values and remained so until December of the same year. In December, the gearbox was replaced due to leaks of oil caused by cracks in the body of the box. From these results it is possible to conclude that, the method developed for the detection of faults in the gearbox detected the failure with six months in advance. Since June 2008 MAE indicator presents high values, indicating something is wrong with the equipment [7].

Table III presents the simulation results of the application of the neural network tool to a gearbox with problems.

The substitution of the gearbox occurred in October 2008. Since July 2008 MAE is becoming high and near of the limit value of $2{ }^{\circ} \mathrm{C}$. In this case, the fault was detected with 2 months in advance.

TABLE III.

SIMULATION FOR A WIND TURBINE WITH PROBLEMS IN GEARBOX - B

\begin{tabular}{|c|c|c|c|}
\hline & $\mathbf{2 0 0 6}$ & $\mathbf{2 0 0 7}$ & $\mathbf{2 0 0 8}$ \\
\hline Jan & 1.088 & 1.253 & 1.584 \\
\hline Feb & 1.067 & 1.586 & 1.902 \\
\hline Mar & 1.063 & 1.197 & 1.697 \\
\hline Apr & 1.148 & No data & 1.499 \\
\hline May & 1.208 & 1.193 & 1.441 \\
\hline Jun & 1.212 & 1.291 & 1.464 \\
\hline Jul & 1.071 & 1.319 & 1.667 \\
\hline Aug & 1.02 & 1.299 & 1.909 \\
\hline Sep & 1.315 & 1.410 & 2.968 \\
\hline Oct & 1.397 & 1.600 & 4.011 \\
\hline Nov & 1.332 & 1.594 & 5.581 \\
\hline Dec & 1.135 & 1.640 & 4.159 \\
\hline
\end{tabular}

As it is also possible to see, after the substitution of the gearbox, MAE values are still high and very distant from the limit value. This is synonymous of new equipment different from the previous. The new gearbox was not of the same model of the substituted.

For the same wind park this new method was applied in the detection of faults in the electrical generator. Two of the 13 wind turbines had problems with the electrical generator that lead to the substitution of the equipment.

According to the quality of the measurements and the performance of the method, the trigger limit used for MAE to inform that there is a big probability of fault in the equipment is $5^{\circ} \mathrm{C}$.

TABLE IV.

SIMULATION FOR A WIND TURBINE WITH PROBLEMS IN ELECTRICAL GENERATOR - A

\begin{tabular}{|c|c|c|c|c|}
\hline & $\mathbf{2 0 0 6}$ & $\mathbf{2 0 0 7}$ & $\mathbf{2 0 0 8}$ & $\mathbf{2 0 0 9}$ \\
\hline Jan & 5.219 & $\mathbf{4 . 8 0 3}$ & & \\
\hline Feb & 5.027 & $\mathbf{3 5 . 0 3 2}$ & & \\
\hline Mar & 5.220 & & & \\
\hline Apr & 4.572 & no data & & \\
\hline May & 2.924 & & & \\
\hline Jun & 2.889 & & & \\
\hline Jul & 2.828 & & & \\
\hline Aug & 3.414 & & & \\
\hline Sep & 3.858 & & & \\
\hline Oct & $\mathbf{5 . 1 9 4}$ & & & \\
\hline Nov & $\mathbf{4 . 4 5 7}$ & & & \\
\hline Dec & $\mathbf{5 . 4 3 0}$ & & & \\
\hline
\end{tabular}

Table IV presents the simulation results for wind turbine with problems in the electrical generator.

In October 2006 the MAE values are consecutively high and in February 2007 service reports inform that there was an short-circuit in the rotor windings and the necessity of substituting the equipment

As it is possible to see since October MAE was high and limit of $5^{\circ} \mathrm{C}$ was exceeded. This can be interpreted has an alarm of a problem in the generator given with 4 months in advance.

As is possible to see to, in the first three months of 2006, MAE is high. At the end of March cables of the slip ring were substituted, because were damaged. This method detects also, with good accuracy, this type of problems of electrical generator.

Another example of application of the method on the detection of an electrical generator fault is presented in Table $\mathrm{V}$. 
TABLE V

SIMULATION FOR WIND TURBINE WITH PROBLEMS IN ELECTRICAL GENERATOR - B

\begin{tabular}{|c|c|c|c|c|}
\hline & $\mathbf{2 0 0 6}$ & $\mathbf{2 0 0 7}$ & $\mathbf{2 0 0 8}$ & $\mathbf{2 0 0 9}$ \\
\hline Jan & $\mathbf{5 . 7 6 5}$ & 4.901 & 2.360 & \\
\hline Feb & $\mathbf{5 . 7 4 1}$ & 3.532 & 3.485 & \\
\hline Mar & $\mathbf{4 . 0 1 7}$ & 3.628 & 3.835 & \\
\hline Apr & $\mathbf{4 . 4 4 2}$ & no data & 2.989 & \\
\hline May & 3.076 & 3.392 & 2.284 & \\
\hline Jun & 3.253 & 4.002 & 2.487 & \\
\hline Jul & 2.878 & 4.058 & 2.750 & \\
\hline Aug & 2.635 & No data & 3.049 & \\
\hline Sep & 3.169 & No data & 2.950 & \\
\hline Oct & 3.796 & 2.346 & $\mathbf{4 6 . 9 1}$ & \\
\hline Nov & 3.670 & 2.343 & & \\
\hline Dec & 3.829 & 2.864 & & \\
\hline
\end{tabular}

In the first months of 2006, MAE was high indicating possible problems with the electrical generator. In April 2006 maintenance service reports, indicate that slip ring cables were damaged and needed substitution. Since January that the monitoring method indicates, that something was wrong with that equipment.

In October 2008, MAE increased significantly and big electrical problem occurred with the equipment without detection by the developed tool.

With a deeper analysis of this fault using the information contained in the service reports made by the maintenance teams was possible to understand that in October 11, a maintenance team was inspecting the wind generator because of problems flagged by the SCADA system and in October 15 the problem was detected. In order to try to detect the specific day problem occurred; the informatics tool was run each September day. Simulation results are presented in Table VI

TABLE VI

SIMULATION FOR WIND TURBINE WITH PROBLEMS - B

\begin{tabular}{|c|c|c|c|c|}
\hline Day & MAE & & Day & MAE \\
\hline $\mathbf{1}$ & 1.503 & $\mathbf{9}$ & 2.571 \\
\hline $\mathbf{2}$ & 1.651 & $\mathbf{1 0}$ & 3.074 \\
\hline $\mathbf{3}$ & 2.609 & $\mathbf{1 1}$ & 3.791 \\
\hline $\mathbf{4}$ & 1.744 & $\mathbf{1 2}$ & $\mathbf{5 . 9 1 8}$ \\
\hline $\mathbf{5}$ & 3.446 & $\mathbf{1 3}$ & $\mathbf{5 . 8 1 5}$ \\
\hline $\mathbf{6}$ & 2.154 & $\mathbf{1 4}$ & $\mathbf{5 . 9 9 7}$ \\
\hline $\mathbf{n n n}$ & 2.172 & $\mathbf{1 5}$ & $\mathbf{6 . 2 5 4}$ \\
\hline $\mathbf{8}$ & 2.273 & $\mathbf{1 6}$ & $\mathbf{8 . 6 2 3}$ \\
\hline
\end{tabular}

After September 16 there are no more measurements collected by SCADA system. As is possible to see, if this tool run day by day, the problem could be detected in September 12 , i.e. one month in advance, and maybe equipment could be saved without need of substitution.
This new detection tool was also tested in a bigger wind farm with different wind turbines in order to detect gearbox problems. In this wind park did not occurred serious problems with gearboxes, only small ones. Another difference is the absence of sufficient information. The period of analysis was only 2 years, which was a problem because data available to train the neural network was insufficient, in some cases.

Table VII shows the simulation results for a wind turbine with some problems in the gearbox.

TABLE VII

SIMULATION FOR WIND TURBINE WITH PROBLEMS GEARBOX - A

\begin{tabular}{|c|c|c|}
\hline & $\mathbf{2 0 1 2}$ & $\mathbf{2 0 0 7}$ \\
\hline Jan & & $\mathbf{1 , 0 7 6 7}$ \\
\hline Feb & & $\mathbf{1 , 1 8 2 8}$ \\
\hline Mar & & $\mathbf{1 , 2 0 9 8}$ \\
\hline Apr & & 0,7050 \\
\hline May & & 0,6283 \\
\hline Jun & & 0,6486 \\
\hline Jul & & 0,6729 \\
\hline Aug & & 0,6868 \\
\hline Sep & & 0,6683 \\
\hline Oct & & 0,6869 \\
\hline Nov & 0,8572 & 0,8376 \\
\hline Dec & 0,8209 & 0,8132 \\
\hline
\end{tabular}

In this case, service reports made by maintenance teams inform that 2 problems had occurred in this wind turbine. One happened in February 11 and the other in March 25. As it is possible to see, MAE is higher than normal since January, this can understand that has a possible fault occurring in the gearbox. Another interesting thing obtained from the analysis of results is that the first fault was not solved correctly because a second fault happened in March. This is another advantage of this method, i.e. the capacity of measure maintenance performance.

Another example can be seen in Table VIII, were informatics tool was run over information from another wind turbine.

This wind turbine had problems related with low gearbox oil pressure. These problems were registered in October and December of 2013. It is possible to see that since July 2013, the MAE is higher than $1^{\circ} \mathrm{C}$. This can be understood that possible a fault occurred in the equipment. In February and March MAE is high too, but was reported that by the end of February maintenance was performed by maintenance team. This can explain the MAE value, because when maintenance teams are in operation, some tests are made to equipment and those tests can be registered by the SCADA system and measures can be saved in the data set. Normally results obtained by this software tool in the maintenance months must be analyzed with carefully. 
TABLE VIII

SIMULATION FOR WIND TURBINE WITH PROBLEMS GEARBOX - B

\begin{tabular}{|c|c|c|}
\hline & $\mathbf{2 0 1 2}$ & $\mathbf{2 0 0 7}$ \\
\hline Jan & & 1,1534 \\
\hline Feb & & 1,2652 \\
\hline Mar & & 1,0790 \\
\hline Apr & & 0,9760 \\
\hline May & & 0,8645 \\
\hline Jun & & 0,8612 \\
\hline Jul & & 1,0014 \\
\hline Aug & & 1,0186 \\
\hline Sep & & 1,0437 \\
\hline Oct & & $\mathbf{1 , 2 2 1 9}$ \\
\hline Nov & 0,9832 & $\mathbf{3 , 5 7 2 9}$ \\
\hline Dec & 1,0233 & $\mathbf{6 , 3 7 1 6}$ \\
\hline
\end{tabular}

\section{CONCLUSION}

New methods to help on detection of faults in some important equipment's of wind turbines are needed. New methods must not increase operational costs.

Measurements obtained from SCADA systems have a lot of information that is not used in all fullness. This new method presented achieves these goals. It is not expensive and gets useful information from measurements that can be used to make an early detection of faults and with that reduce the downtime due to problems in wind turbines.

One important issue is the necessity of having a large data set and as much information as possible about the equipment performance.
In each analysis it is necessary to define the trigger value of MAE in order to make a good detection of a fault. It was not possible, till now, to define a unique value for MAE that could be used for all analysis. It was possible to see from the results presented in the small wind farm that the limit value of MAE used to detect faults in gearboxes was $2^{\circ} \mathrm{C}$, but in the larger wind farm value used was $1^{\circ} \mathrm{C}$.

Results presented give us hope of used this new nonintrusive method into SCADA systems of wind park operators as help on detection of faults in some important wind turbines equipment's.

\section{REFERENCES}

[1] R. W. Hyers et al., "Condition monitoring and prognosis of utility scale wind turbines," Energy Materials: Materials Science and Engineering for Energy Systems, vol. 1, pp. 187-203, 2006.

[2] J. A. Andrawus, et al., "Wind Turbine Maintenance Optimisation: principles of quantitative maintenance optimisation " Wind Engineering, vol. Volume 31, p. 10, March 2007.

[3] J. Nilsson and L. Bertling, "Maintenance management of wind power systems using condition monitoring systems - Life cycle cost analysis for two case studies," IEEE Transactions on Energy Conversion, vol. 22, pp. 223-229, Mar 2007.

[4] Institute of Electrical and Electronics Engineers, "IEEE 90: IEEE Standard Glossary of Software Engineering Terminology", 1990.

[5] DGGE/CERTIEL, "RTIEBT- Portuguese Regulation for Electrical Installations", 2006.

[6] Wind Measurement International, "Operational and Maintenance Costs for Wind turbines".) [Online]. Available: http://www.windmeasurementinternational.com/wind-turbines/omturbines.php

[7] R. F. Mesquita Brandão, "Assinatura Digital de Aerogeradores", $\mathrm{PhD}$ dissertation, Faculty of Engineering - University of Porto, Porto 2011 (in portuguese).

[8] R. F. Mesquita Brandão, J. A. Beleza Carvalho and F. P. Maciel Barbosa, " Application of Neural Networks for Failure Detection on Wind Turbines," in Proc. 2011 POWERTECH Conf., pp. 246-251. 